\title{
Can Assessment Be a Panacea for All Education's Ills? The Case of an Entrance Examination to Ghana School of Law
}

\author{
Akunu Agbeti \\ Department of Educational Studies, Methodist University College Ghana, P. O. Box DC940, \\ Dansoman-Accra, Ghana
}

\begin{abstract}
The 2019 entrance examination of the Ghana School of Law (GSL) recorded an unusually high failure rate which sparked a vibrant national discourse. This study sought to throw light on the reasons for the mass failure and unsuccessful students' understanding of this experience using documentary sources and interviews. The study found that there was concern about the rising cases of unprofessional practices among legal practitioners and the authorities decided to stop the decline with the entrance examination. The entrance examination was purposefully used to restrict the number of entrants to the professional legal training institution. Also, the students who did not pass the examination felt being treated unfairly but were cowed by the fact of their failure in the examination. The study concluded that the entrance examination was used in a unique way primarily because of the notion of merit inherent in assessment which is also seen as the embodiment of acceptable standard.
\end{abstract}

Keywords: External uses of assessment; Assessment and merit; The appeal of assessment; Entrance examination; Assessment as policy tool.

DOI: $10.7176 / \mathrm{JEP} / 13-2-01$

Publication date: January $31^{\text {st }} 2022$

\section{Introduction}

Educational assessment in its various forms is used for a variety of purposes ranging from the provision of information for use in the course of instruction (Black \& William, 1998) to providing a basis for decisions in the wider society outside the classroom (Porter, 1995). The results of assessment have profound influence on decisions about individuals because they are generally accepted as a pointer to the worth of a person in terms of some capability acquired through education. The capabilities that the results portray which is of interest in many decision making situations outside the classroom are those in the dimensions of knowledge and skills although some believe assessment is used to measure more than achievement (Brink, 2011).

What is not in doubt though is that attributes related to the affective domain such as values, morality and ethical conduct cannot easily be gleaned from examination results. It is in this light that the use of an entrance examination by Ghana School of Law (GSL) in a bid to promote value-laden conduct among lawyers in their postcall professional practice raises curiosity. This article interrogates the extension of the use of the entrance examination to a phenomenon not normally associated with the results of this type of assessment. The question is, why is assessment seen in this instance as the tool to use to remedy the perceived shortcomings in education? The paper is structured in sections. In the second section, the role of assessment in general and of admission tests in particular is briefly discussed. The next section focuses on the 2019 admission test of GSL and what it was intended to achieve. This is followed by the personal experiences of unsuccessful prospective students who took the test. Next, is the discussion of their experiences including the nature of legal education. Finally conclusions are drawn about possible reasons for the relatively unknown use of assessment in this instance.

\section{The Role of Assessment}

Examinations are assessments that are carried out at certain points in time to obtain information that would allow for decisions to be made about the learners. The results of tests can help educators to make decisions about the level of attainment of the learners (Supovitz, 2009; Delandshere, 2001; Brink, 2011). Stakeholders outside the context of educational institutions also use the results to make various decisions about the examinees for purposes such as employment and allocation of common public resources and opportunities. Also, at the level of policy formulation, assessment has been seen as a tool for effecting change in education delivery. For example, it has been observed that external assessment has become the preferred government response to the perceived low quality of education in an increasing number of countries worldwide (Broadfoot \& Pollard, 2000; Phelps, 2000; Amrein \& Berliner, 2002). Besides its educational uses, assessment has been known to be susceptible to social and political uses (Firestone \& Bader, 1992; Stobart, 2008). In view of the multiple uses of assessment it has been advocated that the educational assessment community should devise ways to promote the proper uses of assessment by engaging policymakers and providing them with expert advice (Brink, 2011).

\section{Admission Tests}

In education, assessment is done for different reasons and the results used for different purposes by different groups 
of people (Fullan, 2009; Brink, 2011). It is a common practice to use admission tests to select students into higher institutions of learning. Such tests are founded on the notion of sorting which motivated the development of intelligence testing such that only capable individuals are given the chance. In situations that require the use of admission tests, the selection is usually based on specified criteria which often include a basic pre-qualification such as a second cycle education certificate or a first degree in the case of post-graduate admissions, and the results of the selection test. Selection tests introduce rigor in the selection process and are used in situations where available spaces fall short of the demand or where certain aptitudes are required. In such situations, the quality of entrants is carefully considered because it has implications for the educational institution, the individual student and the wider society (Wikström \& Wikström 2017). Similarly, the fairness of the selection instrument is carefully considered because the inherent qualities of the instrument can either favor or disadvantage groups of people to be selected which can have implications for social ideology (Wolming, 2001). Often, the justification for the use of tests for selection is the proposition that they promote equity in access to educational opportunities because of their objectivity and fairness (Porter, 1995; Linn, 2000; Ağazadea et al., 2014; Bulman, 2015).

The procedure often adopted for selection is to rank applicants either on the pre-qualification requirement or the admission test or a combination of the two. But whichever procedure is adopted has an impact on the individuals admitted because studies have found that various factors and the format of the instrument do impact the results (Zwick 2002, 2004). Whether it is the pre-qualification or the admission test that is used, they both have their critics but it is the use of admission tests, which in most cases are standardized tests, that has been the most criticized in terms of validity and fairness to all groups of applicants (Wikström \& Wikström 2017; Linn, 1990, 2001).

The role basic pre-qualifications and admission tests play in admissions into higher institutions of learning has been studied extensively in the US (Linn, 1990; Zwick, 2002, 2004). In Swedish contexts the focus of this line of research has been on the predictive validity of both school grades (basic-prequalification) and the admission tests. The results generally show that school grades have higher predictive value than the admission tests (Lyrén, 2008; Wolming and Wikström, 2010). According to Wikström \& Wikström (2017), "These findings are consistent with international observations that academic performance is more strongly correlated with school grades than with admissions' test scores" (p.2). The general conclusion from these studies is that the two types of measurements predict differently because in essence, they measure different attributes.

The literature on admission tests is replete with studies on various aspects of the tests as they relate to their impact on admissions and their relationship with the academic performance of students in the higher institutions after their admission (Ağazadea et al., 2014; Bulman, 2015). What is rare, however, is research on a possible relationship between admission tests and performance of individuals after school in the world of work. It is in this light that the use of an admission test as a tool to regulate the ethical conduct of professional lawyers in Ghana is seen as a novelty worthy of inquiry.

\section{The Admission Test of Ghana School of Law}

The Ghana School of Law (GSL) which was established by the General Legal Council in 1958 has remained the sole institution in the country for the training of legal practitioners to this day. To qualify for admission to GSL, the applicant must possess an LLB degree from an institution in a common law jurisdiction (GSL, 2020). Prior to 2003, admission to GSL was fairly straightforward as the number of students graduating from the only Law Faculty at the University of Ghana could be conveniently accommodated. However, the situation changed when many more tertiary institutions, both public and private currently numbering 14, obtained accreditation and are offering LLB degrees. The expansion in the number of the degree awarding institutions has led to an exponential increase in the number of graduates with LLB seeking admission to GSL to pursue the 2-year professional law program. As the GSL has not been expanded to match the increase in the number of potential students seeking admission, it became necessary to introduce an entrance examination seven years ago to serve as the 'gate-keeper' to regulate its admissions (Akapame, 2019). In spite of objections from mainly law students, this examination has persisted, apparently because it has served well the function of controlling access to GSL. For this reason, the entrance examination has assumed very high stakes for potential entrants to this institution.

The entrance examination of GSL which was conducted in 2019 was unique in the sense that its results generated a lot of public interest and has continued to invite public discourse about the nature of professional legal education in the country two years on. What made this entrance examination exceptional was the rather high failure rate recorded. Out of 1,820 LLB graduates who took the examination, only 128 passed and got admission. A whopping 93 percent of the candidates did not pass. This result which was seen as the worst on record sparked protests in various forms from the entire law student population in the country and was picked up by the press and brought to the attention of the public.

Ordinarily, failure in the entrance examination would have passed without notice because it would be understood as inadequate preparation on the part of the prospective students and would not have generated the public interest that it did. But the public statements of the Chief Justice who heads the judicial system including 
legal education in defense of the results drew public attention and generated a vibrant public discourse. From an assessment perspective, the statements did not only confirm the gate keeping role of the examination but also introduced a role that would be of interest to educational assessors and researchers.

At a Bench, Bar and Faculty Conference after the release of the results when the discourse was raging, the Chief Justice was reported by Ghana Web news portal to have said that "any attempt to allow the production of lawyers without efficient control, checks and balances will be rejected irrespective of who is advocating for it." And that "mass production of lawyers will reduce the quality and standards of the profession". The reasoning behind the use of the entrance examination to prune the number of students selected for admission was revealed in the report when the Chief Justice said:

Those of us who have been too long on the General Legal Council, those of us who spent too long on the disciplinary committee, we have cause to worry because the kinds of misconduct are such that there is no way anybody envisaged these categories of misconduct when the Legal Profession Act was being enacted in the $1960 \mathrm{~s}$

Focusing on her concerns about legal education in Ghana, the Chief Justice further stated that, "Those of you lawyers and those of you lecturers who are busy advocating free scale, mass admissions into the professional law course, and mass production of lawyers, be careful what you wish for.” (Ghana Web, 2019).

From the report, it is clear that the Chief Justice had observed a worrying trend and was concerned about the increasing levels of misconduct among practicing lawyers. Obviously she was determined to ensure that remedial action was taken to reverse the trend. However, the catch was the belief that drastically reducing the number of students admitted to the law school would arrest the decline in ethical practice. The notion of "mass production" of lawyers voiced by the Chief Justice was a show of concern about the perceived declining quality of professional training. As head of the judicial system, the Chief Justice was also aware of the scramble for the available places at the law school arising out of the mismatch with the number of prospective applicants. This situation has created a dilemma which can best be resolved through a concerted effort of the authorities, taking into consideration the balance between the need to expand access to legal education and the provision of quality legal education that would meet the needs of society.

\section{Method of Soliciting Students' Views}

In order to understand how the unsuccessful prospective students felt and the meaning they made of the controversy generated by the mass failure, three of the students who took part in the entrance examination (two males and one female) were contacted and they agreed to separate telephone interviews. Although the use of the telephone deprived the researcher of visual cues that could have enriched the conversations, it was considered the safest method of gathering the information in the midst of COVID-19 pandemic. The participants were purposefully selected because they were known to the researcher as having been part of the student cohort that sat the examination in 2019 but did not gain admission and who also took part in the protest march organized by the National Association of Law Students against the results. Familiarity of the researcher with the participants made it easier for them to open up and freely expressed their views on the issue which many of the prospective students would not want to do openly for fear of being noticed by the legal authorities. The participants agreed and shared their experiences at their convenience after assurances of anonymity. The interviews which lasted for about 30 minutes each were revealing and provided insight into how they felt about the examination and the meaning they made of the ongoing discourse. Not unexpectedly, they all expressed similar views and sentiments about the entrance examination probably because they all saw the examination as standing between them and the attainment of their desires to become practicing lawyers. Their views were thus merged to provide a clear understanding of their experiences.

\section{Experiences of Unsuccessful Prospective Students}

The conversations between the Researcher (R) and the students code-named Musah (M), Jack (J) and Esther (E) revealed that the students were upset about their failure in the entrance examination. They did not understand why the examination would be set in such a way that only few students could pass. In the view of the students, it was a deliberate act by those in charge of legal education to restrict access to the professional law course and thereby restrict the number of people who would qualify to practice as lawyers. This is evident in the following excerpts of the interview with Musah (M).

R: Did you take part in the Ghana School of Law entrance exam in 2019?

M: Yes, I did.

$\mathrm{R}$ : Were you one of those who failed the exam?

M: I don't like that expression of failed the exam. It was a deliberate attempt to limit the number of people who want to become lawyers, that's all. How can you conduct an exam for 1820 and only 128 will pass? It means it's a deliberate attempt to cut down the number, and that's not fair.

$\mathrm{R}$ : Why do you think the number of lawyers is being reduced? 
M: The old people don't want the young ones to come and compete with them for the cases they handle in court. But if they don't want more lawyers why did they allow the universities to run law courses?

R: But if you can't pass the entrance exam then you don't qualify to enter the profession.

M: How can you go into an exam without knowing what will be tested?

R: How so? Was there no information about what to expect in the exam?

M: They only listed the courses we studied at the university, such as criminal law, law of contracts, etc. Look, you have more than 2,000 cases and it is not possible you can cover all of them. Then they bring an obscure case that you haven't read before. It will be by sheer luck that a case you read will come in the exam. If you didn't pass it doesn't mean you are not good, you were just not lucky. Even some of our lecturers were surprised that the brilliant students in their classes could not pass the entrance exam, so they joined us in the demonstration.

Musah was clearly not amused that he was referred to as having failed the examination. To him, although he was not successful, he did not consider himself to be a failure. By this he meant that he saw himself as capable of training to become a lawyer except that the examination was deliberately placed in his way. His understanding of the situation was that the examination was not a valid tool for determining ability to pursue the professional law course but rather a tool purposely used to keep down the numbers. This view agrees with the position of the Chief Justice who was against the mass production of lawyers.

Inherent in Musah's answer though, is the tacit acceptance that his inability to gain admission to GSL was occasioned by his inability to do well in the entrance examination. This acceptance is significant in the sense that performance in the examination is the only way to judge objectively the fairness or otherwise of not admitting him to the institution. In his understanding, although the wide field of study in preparation for the examination was the problem, he accepted the fact that he did not do well and did not merit a place.

From her account, Esther also disapproves of the way the examination was used to prevent her from entering GSL. In her view, the system of legal education has become outdated and unable to cope with current demands. This view coincides with that of the Chief Justice which implied a deliberate use of the examination to cut down intake. The point of divergence is the reason for using the examination in this manner. While the student was concerned about the fairness of limiting the intake, the Chief Justice was looking beyond the numbers at how to deal with the nature of professional legal education so as to turn out ethical practitioners.

The following excerpt shows how Esther expressed this view:

R: So, why did the students go on demonstration against the exam results?

E: It's because of the frustration of the large number of students who were denied the chance to enter the law school. The whole legal education structure needs to change. The law school can set the professional exam and allow the universities to prepare the students to take the exam. The role the law school has been playing since independence, to teach and examine lawyers has outlived its usefulness. Here we are, the facilities of the law school have not been expanded but there are many who qualify to train as lawyers. So there must be a rethink of the system.

It is clear that the student agrees that there is the need to review the legal education regime. However, her focus is more on the assessment rather than the nature, focus and delivery of the course. Both the Chief Justice and the students have interest in the assessment but for different reasons. While the policy maker was looking at the selection function of the exam, the students were concerned about how it would be made easily accessible to prospective students.

Jack $(\mathrm{J})$, on his part was clear about the distinction between cognitive and affective domains of learning and by extension the way to measure them. To him, the instrument for assessing the affective domain is not the same as that for assessing content knowledge which is required in the entrance examination. This view is in contrast with that of the Chief Justice who saw the entrance examination as the tool for selecting students who would come out to become more ethical in their practice of the law.

This distinction is evident in the following dialogue:

R: The Chief Justice defended the results at a Bar, Bench and Faculty Conference last year and said it was necessary to limit the number of lawyers because of the increasing inappropriate professional conduct of lawyers these days.

J: I haven't heard about the justification. But that can't be right. Naturally, as numbers increase there will be increase in cases of infractions. It's a human thing. But limiting intake will not eliminate that human element. $\mathrm{R}$ : There is a course on ethics during the professional training. Could it be that lawyers passed this course but are not practicing with its tenets?

$\mathrm{J}$ : Well, you know, passing exams is a different thing from putting what you learnt into practice. So a different way should be found to deal with this issue which I will call a moral issue. It is not right to use that to deliberately deny a whole lot of people access to the professional course.

This divergence in the viewpoints of Jack and the Chief Justice is indicative of how stakeholders view the role of assessment in different ways depending on their needs and expectations of the outcome. 


\section{Discussion of the Findings}

The discussion is in two parts. The first part focusses on what is expected of the GSL entrance examination and how it became a policy tool for access control to professional legal training. The second part elucidates how legal education has been delivered in some jurisdictions and how similar concerns to those expressed by the Chief Justice were dealt with in different contexts. The common thread that runs through legal education which the Ghanaian authorities were also grappling with are identified and the approach adopted interrogated.

\subsection{Expectations of the GSL Entrance Examination}

Clearly, the entrance examination of GSL was purposefully used by the authorities to address a perceived shortcoming in the professional practice of lawyers. The legal authorities were of the view that the root cause of the shortcomings observed in the conduct of lawyers resided in their training. Apparently the number of trainees was seen as the culprit and therefore targeted for remediation through the entrance examination. The use of the examination as the tool to effect the desired change in professional practice transcends the conventional uses of an entrance examination which is expected to produce information about the cognitive ability and aptitude of individuals that would enable the individual successfully complete the program (Linn, 1990; Zwick, 2002; Bulman, 2015). In this case, the examination was used as a tool for the implementation of a policy to correct defects in ethical professional practice but doing so indirectly through reduction in the number of students admitted. What is not clear is whether reducing the intake in itself would be enough to produce the intended outcome of inculcating values and morality in the students which would later translate into their practice of the law. This use of the examination cannot be situated in measurement-driven instruction either since the entrance examination precedes instruction.

What is of interest in this situation is to determine what it is about the examination in the midst of the other factors in the educational setting that made it possible for it to be deployed in a manner that does not find support in the literature. The answer could be gleaned from Musah's response: "How can you go into an exam without knowing what will be tested?" This is an admission that he did not answer the question on the case well enough to merit a place in the school. Apparently, the same appeal of merit inherent in the examination made it possible for the authorities to use it to perform a function that is not known in the literature. A paper-and-pencil test of the kind used for the entrance examination, made up of 20 multiple choice and one essay (case) question, would best test cognitive capabilities. The same examination would not be suitable for judging the predisposition of prospective students when it comes to affective qualities such as empathy, morality and values which are seen as desirable qualities needed in professional law practice but increasingly dwindling among practitioners.

In the view of Musah, he could not obtain the pass mark because of the undefined scope of the examination. This means that if the area of coverage was clearly defined, he would have covered the relevant cases and be able to perform well. The undefined scope would appear to be a deliberate strategy to exploit the element of uncertainty by placing it in tandem with merit to achieve the policy of limiting the number to be admitted.

From all indications, the notion of merit inherent in examinations was the point of attraction. Generally, the appeal of merit subdues public scrutiny of examination results and if candidates do not pass, there is not much to say in their favor since it is assumed that they did not meet the required standard. This was evident in the public discourse surrounding the results of the entrance examination. Virtually none of the grounds for criticism was directed at the nature of the examination. Not even Esther who, in essence, questioned the fitness for purpose of the examination would discount the notion of merit.

\subsection{Legal Education in Perspective}

In a broad sense, legal training is intended to form well balanced professionals because 'Being a lawyer involves... being able to reason like a lawyer, even more than having detailed knowledge of particular sets of rules' (Hage et al., 2017). Reasoning like a lawyer connotes practicing law in a professionally acceptable, socially conscious and ethically desirable manner because possession of head knowledge of rules alone does not make one a good lawyer. For this reason, the expectation is that lawyers will be trained to acquire the basic values of remaining faithful to the ethics of the profession, being conscious of the need to promote justice, fairness, and morality and the duty to uphold the dignity and work toward the betterment of the legal profession (Rougeau, 2009). It is the duty of providers of legal education to train well rounded students who would hold on to these primal values in their practice. The professional course at the Ghana School of Law includes a compulsory course in Ethics in the second and final year of training (GSL, 2020). This course is intended to equip trainees with the ethical aspect of the profession without the inclusion of the aspect of morality and values. It would appear that the rampant unacceptable conduct of lawyers complained of by the Chief Justice and which led to disciplinary actions could be traced to the limited scope of this course and its lack of effectiveness in inculcating the expected values.

Faced with similar concerns about how to train students to acquire values, efforts were made by some training institutions to make awareness of values a part of students' educational experiences while in school and various programs have been developed for that purpose. For example, as a way of reorienting erring students to realign 
their personal values with the values of the campus community, some colleges in the US have designed special courses for that purpose. Students who violate institutional rules and codes of behavior are required to undertake the course as part of the sanction. The intended outcome of such courses is educational rather than punitive as they are meant to enable the erring students to reconsider their values and the resultant actions in relation to the values that bind the university community together. The results of this approach to dealing with deviant behavior have been found to be generally positive as only very few such students repeated the offences (Pontious, 2008). The aim of this strategy is to train students to acquire the mindset of self-regulation and ethical behavior while in school in the hope that it would stick with them through their working lives. Such institutional measures assist those trainees with lower levels of moral development to appreciate the importance of belonging and conforming to the rules of their future community of practice.

van Ommen et al. (2017) recommend the use of drama episodes as audio-visual aids to teach morality when training professionals such as lawyers, medical practitioners and developmental psychologists. They believe that using episodes involving ambivalent moral characters as a point of discussion provides a vista of the kind of moral complexities that the students would have to deal with in professional practice. In their view, the pedagogical value of this approach is that "[it] enables teachers to engage in discussions about what certain professional rules and regulations mean, why they are in place, and whether students understand them correctly, hopefully creating an even better ethical awareness within a new generation of professionals." (p.392)

Rougeau, (2009) on his part dilates on the quest for justice as being fundamental to good lawyering and how this can be attained through a service oriented legal education. In his view there are three facets of the concept of justice. These are commutative justice which deals with fairness of dealings between individuals and between groups; distributive justice which deals with adjustments in the allocation of essential resources such that no one is deprived of them; and social justice which focuses on the provision of opportunity for every person to take part meaningfully in the life of their communities. Observing that American legal education is fixated on commutative justice with scant attention to the other two, he recommends a community interaction program which affords law students the opportunity to work together with people in the lower stratum of society as part of their training. He believes that this experiential learning approach is advantageous as it "offer[s] students an opportunity to develop skills and values that make clear the integral role lawyers must play in assuring access to justice for all members of society"(p.1).

Clearly, the rising cases of unprofessional practice noticed by the Chief Justice which provoked the use of the entrance examination to find a solution could be traced to the training of the lawyers. There is meeting of minds among legal educators that training holds the key to remedying deficiencies in legal practice in terms of values and ethics. Commenting on the nature of legal education in the US for over a century, Rougeau, (2009) cited the Carnegie Report of 2007 which identified the shortfalls in the way students are taught during their training as follows:

Issues such as the social needs or matters of justice involved in cases do get attention in some case-dialogue discussions, but these issues are almost always treated as addenda. Being told repeatedly that such matters fall, as they do, outside the precise and orderly "legal landscape," students often conclude that they are secondary to what really counts for success in law school - and in legal practice. In their all-consuming first year, students are... warned not to let their moral concerns or compassion for the people in the cases they discuss cloud their legal analyses (p.7).

The kind of training regime described above would produce lawyers who see moral and ethical issues as secondary. Having been cast in this mold, it did not come as a surprise that the role of lawyers in the economic meltdown of 2008 and the accompanying financial crisis came under scrutiny. From all indications, the way the students were trained laid the foundation for their practice. The influence of legal education that is focused on teaching the transactional value of law must have developed practitioners who were less mindful of the social, moral and ethical aspects of their practice as observed by the Chief Justice in Ghana. What this means is that it is the philosophy and practical delivery of legal education that is responsible for the falling moral and ethical standards and for this reason, the solution lies in revisiting the mode of training lawyers to bring into the main stream the moral, social and value-laden qualities that truly successful practice demands. The problem of rising professional misconduct among lawyers which is a manifestation of some deficiency in morality and values and which required remedial action is thus an issue that lies largely with the training of the lawyers. To deal effectively with this problem requires an appreciation of the nature of current legal education and how it can be reformed to produce practitioners who are conscious of the moral, social and ethical obligations placed on legal practitioners.

\section{Summary and Conclusion}

Assessment has been used by policymakers since the middle of the nineteenth century to demand better performance from schools whenever concern has been raised about the quality of education and the use of assessment as a tool for reforming education has remained popular with reformers in many countries. This could be the case because assessment provides a socially acceptable and subtle means for the powerful in society to 
exercise control over education for social and economic reasons, and legitimating it through the appeal of meritocracy which is embodied in assessment. The Ghana School of Law (GSL) admission examination in 2019 could be said to be a typical case of the political use of assessment.

The choice of an entrance examination by GSL to deal with an issue that goes beyond the classroom to posttraining professional practice appears to be a novelty. As to how an entrance examination that limits the number of entrants would on its own ensure the development of moral, social and ethical values that could be applied by the lawyers in their professional practice is farfetched. It is known that assessment can be used for various educational, social and political purposes but the role assigned to it in this instance does not find support in the literature. If perhaps there exists a relationship between the entrance examination and ethical professional practice, it is yet to receive scholarly attention.

Clearly, there was an issue with the values, morality and ethical professional practice of an increasing number of lawyers in Ghana. The increasing professional infractions noticed by the Chief Justice were overwhelming and something drastic needed to be done to reverse the situation. It would appear that the unprofessional practices were recognized as the effects of the kind of training given to the lawyers because that is what would make them rounded practitioners who did not only know the rules but were also conscious of the acceptable norms, ethics and values that were expected in acceptable legal practice.

Again, there was a realization that reversing the falling professional standards lay within the remit of education and training and the required remedial action needed to be taken in that domain. Examples exist of how some professional training institutions are adopting innovative methods and introducing programs that would make their trainees acquire the desired knowledge and value dispositions that would make legal practice more acceptable and socially responsible. Apparently, the current training regime of GSL focuses on the transactional value of legal practice that deals with commutative justice with little attention to morality, societal and ethical considerations and that is what the Chief Justice sought to deal with.

However, the tool chosen by GSL to deal with this challenge although educational, has generated a lot of controversy. The large number of students who failed the entrance examination were not convinced that the examination was valid and expressed doubts about the official reason for the failures, which is the inability of the candidates to do well in the examination. The students further contest the large failure rate and attribute it to an undeclared policy to limit the number of student intake. If the legal education authorities wanted to effect changes in professional practice, then GSL missed the real tool which is a change in the orientation and delivery of a curriculum that would give more attention to the desired values, attitudes and mindset that the trainees need in the hope of ensuring desirable behavioral patterns in professional practice. Apparently, the authorities in charge of legal education intended to reduce the number of students admitted to the level that the school's facilities can conveniently accommodate which is a legitimate use of entrance examinations. It would appear that the authorities of GSL chose not to openly declare this policy in order to avoid drawing public attention to the inadequacies of the facilities to cope with large numbers because they have not been expanded over the years to match the increasing number of students. It is to avoid the expected unfavorable public discourse that knowledge of the state of the facilities would generate that the authorities chose the entrance examination as the tool to effect the policy change but labelled it as a quality improvement measure.

Two reasons can account for this choice. Firstly, changing the nature of assessment is quick to implement and the results are immediately visible. Secondly, and more importantly, the notion of merit inherent in assessment lends legitimacy to the use of the examination in this manner. Ordinarily, when a student fails an examination it is understood that $\mathrm{s}$ /he did not meet the required standard. As to whether or not the examination is fit for purpose is not something that users of the results outside the classroom would concern themselves with and not many users would consider the validity of a test when taking decisions based on the results. The assumption is that the examining institution must have done what is right. This could be the case because the technicalities and confidentiality surrounding examinations put them out of reach to the public. The aura of merit and fairness surrounding especially high stakes examinations for learners make it possible for them to be used as tools to achieve purposes that may not necessarily relate to achievement or aptitude as is the case with the GSL entrance examination. Usually, it is difficult to argue against merit as issues of equity and equality of opportunities take center stage in many societies.

The case of the 2019 entrance examination of GSL being used as a policy tool presents a peculiar instance of using assessment to achieve a purpose that is not directly related to education. What this means is that it is possible to enlist assessment for purposes other than those of immediate relevance to education, in this case, a declared attempt to regulate professional legal practice. This case lends credence to the observation of Firestone \& Bader (1992) that assessment can also be used for social and political purposes. It can be concluded that what made it possible for Ghana School of Law to use the entrance examination for a purpose not directly related to education delivery is the appeal of merit and fairness assigned to assessment. The legal authorities took advantage of these qualities to achieve their policy goal because that would make the impact educationally defensible and socially acceptable. 


\section{References}

Ağazadea, A.S., Canera, H., Hasipoğlua, H.N., \& Civelek, A.H., (2014). Turkish University Entrance Test and academic achievement in undergraduate programs: a criterion-related validity study, Procedia - Social and Behavioral Sciences. 116, 4582-4590.

Akapame, C.K. (2019). Why Ghana's plans to reform its legal profession are flawed. Retrieved from https://theconversation.com/why-ghanas-plans-to-reform-its-legal-profession-are-flawed-125293 (July, 2021).

Amrein, A. L., \& Berliner, D. C. (2002). High-stakes testing, uncertainty, and student learning. Education Policy Analysis Archives. 10(18). Retrieved from http:// epaa.asu.asu.edu/epaa/v10n18.

Black, P., William, D. (1998). Inside the Black Box: Raising Standards Through Classroom Assessment. Phi Delta Kappan. 80, 139.

Brink, C. S. (2011). A Historical Perspective of Testing and Assessment Including the Impact of Summative and Formative Assessment on Student Achievement. Dissertations. 409. Retrieved from https//aquila.usm/dissertations/409.

Broadfoot, P. \& Pollard, A. (2000). The Changing Discourse of Assessment Policy: The Case Of English Primary Education in: A. Filer (Ed). Assessment: Social Practice and Social Product, London, Routledge Falmer.

Bulman, G. (2015). The Effect of Access to College Assessments on Enrollment and Attainment, American Economic Journal: Applied Economics, 7(4): 1-36 http://dx.doi.org/10.1257/app.20140062.

Delandshere, G. (2001). Implicit Theories, Unexamined Assumptions and the Status Quo of Educational Assessment. Assessment in Education. 8, 3, 113-133.

Firestone, W., \& Bader, B. (1992). Redesigning teaching: Professionalism or bureaucracy? Albany, NY: SUNY Press.

Fullan, M. (2009). Large-scale reform comes of age. Journal of Educational Change. 10, 101-113.

Ghana Web, (2019). Retrieved from https://www.ghanaweb.com/GhanaHomePage/NewsArchive/128-out-of1820-pass-law-school-entrance-exams-783396 (July, 2021).

Ghana School of Law, (2020). History. Retrieved from https://gslaw.edu.gh/about-2/history (July, 2021).

Hage J, Waltermann A. \& Akkermans B, (Eds) (2017). Introduction to Law, (2nd ed), Springer: doi 10.1007/9783-319-57252-9.

Linn, R. L. (1990). Admissions testing: recommended uses, validity, differential prediction, and coaching. Appl. Meas. Educ. 3, 297-318. doi:10.1207/ s15324818ame0304 1.

Linn, R. L. (2000). Assessments and accountability. ER Online. 29(2). Retrieved from http://www.aera.net/pubs/er/arts/29-02/linn01.htm.

Linn, R. L. (2001). A century of standardized testing: controversies and pendulum swings. Educational Assessment. 7, 27-38. doi:10.1207/S15326977EA0701_4.

Lyrén, P.-E. (2008). Prediction of academic performance by means of the Swedish scholastic assessment test. Scand. J. Educ. Res. 52, 565-581. doi:10.1080/00313830802497158.

Phelps, R. P. (2000). Trends in Large-Scale Testing Outside the United States, Educational Measurement; Issues and Practice. 19, 11-21.

Pontious, M. W. (2008). Calling the Shots: Using a Required Ethics Course to Promote Intentional Moral Development in Student Conduct Violations, Journal of College and Character. 9(5), 115-121. doi: 10.2202/1940-1639.1682.

Porter, T. (1995). Trust in numbers: The pursuit of objectivity in science and public life. Princeton, NJ: Princeton University Press.

Rougeau, V. D. (2009). Reforming the Legal Profession Through Faith Based Service Learning for Law Students: Notre Dame's "Just Communities" Project, Journal of College and Character. 10(7), 23-26. doi: 10.2202/1940-1639.1439.

Sacks, P. (2000). Standardized minds: The high price of America's testing culture and what we can do to change it. Cambridge, MM: Perseus Publishing.

Stobart, G. (2008). Testing Times. The uses and abuses of assessment. Oxford, UK, Routledge.

Supovitz, J. (2009). Can high stakes testing leverage educational improvement? Prospects from the last decade of testing and accountability reform. Journal of Educational Change. 10, 211-227.

van Ommen, M., Daalmans, S., Weijers, A., Eden, A., de Leeuw, R. N. H. \& Buijzen, M. (2017). A vigilante serial killer as ethics educator? An exploration of Dexter as a tool for moral education in the professional domain, Journal of Moral Education. 46(4), 378-395. doi: 10.1080/03057240.2017.1338558 T.

Wikström, C. \& Wikström, M. (2017). Group Differences in Student Performance in the Selection to Higher Education: Tests vs Grades, Frontiers in Education. 2(45). doi: 10.3389/feduc.2017.00045.

Willingham, W., \& Cole, N. (1997). Gender and Fair Assessment. Mahwah, NJ: Lawrence Erlbaum Associated.

Wolming, S. (2001). Validering av urval [Validation of Selection], (Unpublished Ph.D. thesis) Department of Education, Umeå University, Umeå. 
Wolming, S., \& Wikström, C. (2010). The concept of validity in theory and practice. Assessment in Education Principles Policy and Practice. 17, 117-132. doi:10.1080/ 09695941003693856.

Zwick, R. (2002). Fair Game? The Use of Standardised Admissions Tests in Higher Education. New York: Routledge Farmer.

Zwick, R. (ed.) (2004). Rethinking the SAT. The Future of Standardised Testing in University Admission. New York: Routledge. 